\title{
Gait apraxia after bilateral supplementary motor area lesion
}

\section{S Della Sala, A Francescani, H Spinnler}

See end of article for

authors' affiliations

(The authors are listed in

alphabetical order)

$\ldots \ldots \ldots \ldots \ldots \ldots$ Objectives: The study aimed at addressing the issue of the precise nature of gait apraxia and the cer-

Correspondence to:

Professor S Della Sala,

Department of Psychology,

University of Aberdeen,

AB24 2 UB Aberdeen, UK;

sergio@abdn.ac.uk

Received 3 April 2001

In revised form 28 August

2001

Accepted 3 September

2001

ebral dysfunction responsible for it.

Methods: The case of a patient, affected by a bilateral infarction limited to a portion of the anterior cerebral artery territory is reported. The patient's ability to walk was formally assessed by means of a new standardised test.

Results: Due to an anomaly within the anterior cerebral artery system, the patient's lesion was centred on the supplementary motor regions of both hemispheres. He presented with clear signs of gait apraxia that could not be accounted for by paresis or other neurological deficits. No signs of any other form of apraxia were detected.

Conclusions: The clinical profile of the patient and the analysis of 49 cases from previous literature suggest that gait apraxia should be considered a clinical entity in its own right and lesions to the supplementary motor areas are responsible for it.

G ait disorders are a common feature of several neurological (for example, Parkinson's disease) and psychiatric diseases (for example, schizophrenia). Disturbances of gait that cannot be readily accounted for by abnormalities often occurring in old age (for example, bone and joint degeneration, muscle wasting, or arteriosclerosis obliterans of the lower limbs), pyramidal or sensorial deficits, ataxia (cerebellar, vestibular, or proprioceptive), dystonias or dyskinesias (due to diseases involving the basal ganglia), nor by psychosis, are often referred to as "gait apraxia" (GA)*.20-24

Meyer and Barron ${ }^{23}$ defined GA as "the loss of ability to properly use the lower limbs in the act of walking" (p 279). The syndrome is composed of a mixture of signs including disequilibrium, locomotor abnormalities, inappropriate postural responses, and loss of gait ignition. Gait, stance, and trunk movements are all complex and highly practised. ${ }^{25}$ The respective contribution of each one of these components is often hard to disentangle from that of the others (Rumpf, Stand und Gangapraxie, trunk, stance, and gait apraxia ${ }^{626}$ ).

Indeed, Lang $\mathrm{e}^{27}$ maintained that in GA ideomotor apraxia of limbs is not relevant and that all segments involved intertwine to perform a given movement. Moreover, Nutt et al ${ }^{20}$ maintained that the severity of each individual sign constituting gait apraxia varies from patient to patient.

*The syndrome of GA has been named differently by different authors-for example, "Torso apraxie" (trunk apraxia') or "déséquilibration frontale" (frontal imbalance 2 ). Some of the other labels conformed to the core deficit found-for example, "trepidante abasie", 3 "eingentümliche Ungeschicklichkeit" (remarkable clumsiness ${ }^{5}$ ),

"bewegungstechnische Schwierigkeit" (loss of the technical requirements of the movements ${ }^{6}$ ), "Tapsigkeit" (gawky movements'), "Unbeholfenheit"

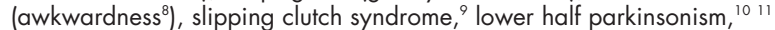
gait ignition failure. ${ }^{12}$ Some other labels referred to the authors' interpretation of GA-for example, melokinetic apraxia, 13 "frontale ataxie" (frontal ataxia ${ }^{14}$ ), "gliedkinetische apraxie" (limb-kinetic apraxia, quoted by Westphal, 15 "motorische Apraxie", ${ }^{16}$ "corticale apraxie", ${ }^{17}$

"innervatorische Apraxie" (innervatory apraxia"), "bilaterale motorische Apraxie", ${ }^{18}{ }^{19}$ frontal gait disorder, ${ }^{20}$ higher level gait disorder. ${ }^{21}$ However, these different terms, often derived from different conceptualisations of gait disorders, define syndromes that overlap more than is usually admitted.
The trunk component of GA encompasses disturbances such as deficits of rising from sitting, sitting down, lying down, turning around while standing, or rolling over in bed. Disturbances of stance encompass deficits of balance while either standing in an upright position, walking, or in negotiating turns. They also include the loss of anticipatory and reactive postural responses resulting in falls. ${ }^{22}{ }^{28}$ Gait disorders comprise deficits of ignition (frozen foot) and stepping, including shuffling, obstructive leg crossing, ${ }^{22} 29$ or leg hypokinesia. Other signs characterising gait disruption include bizarre, counterproductive, and perseverative leg movements, such as the leg's Witzelsucht, ${ }^{29}$ dystonias, dyskinesias, and lower limbs hypotonia as well as involuntary temporary arrests of walking.

Some authors interpreted GA as a feature of frontal inertia. ${ }^{30}$ Others $^{31}$ maintained that GA be a misnomer as the deficit should not be interpreted as apraxic. ${ }^{32-34}$

Gait apraxia was seen over a century ago in patients with lesions to the precentral regions of the frontal lobes who were not paretic. ${ }^{1 * *}$ The association between GA and lesions to the frontal lobes has been reiterated ever since. ${ }^{23} 2537$ Moreover, a few authors ${ }^{38-42}$ demonstrated that the link between trunk movement disturbances and left parietal lesions is weak with respect to other apraxias (but see Poeck et $a l^{43}$ for a different view).

However, the precise nature of GA and the cerebral dysfunction responsible for it have been matters of considerable debate. ${ }^{728445}$ The association between gait disturbances

${ }^{*}$ Bruns ${ }^{14}$ quoted the work of earlier authors who noted the presence of stance and gait disorders in patients with frontal tumours. Among them, he ( $p$ 138) cited Wernicke ${ }^{35}$ who reckoned that a "hesitant gait has been often seen in patients with frontal tumours, it is well possible that in the future this sign will be considered as resulting from a direct insult to the frontal lobes" (p 323). Oppenheim ${ }^{36}$ described gait disturbances in nine of 11 patients with frontal tumours compared with only four of 10 patients with tumours elsewhere in the brain. Bernhardt (quoted by Bruns $^{14} \mathrm{p}$ 138) reported gait disturbances in 18 of 44 patients $(40 \%)$ with frontal tumours but only in five of $41(5 \%)$ patients with extrafrontal tumours. This testifies that the link between gait disturbances and frontal lesions predates the later discussion between its apraxic or ataxic nature. 
and cerebellar damage has been the only accepted knowledge for a long time. Neurosurgeons searched for tumours in the cerebellum solely on the basis of the ataxic appearance of $\mathrm{GA}^{4647}$ only to discover postmortem that sometimes the tumour was sited within the frontal lobes instead.

Some early authors, ${ }^{16} 4849$ following Bruns ${ }^{14}$ suggestion, maintained that the symptoms of GA could aptly be explained in terms of cerebellar imbalance. They interpreted it as due to either a frontopontocerebellar disconnection, ${ }^{50}{ }^{51}$ or to an increased pressure which benumbs the cerebellum. ${ }^{52}$ Frazier $^{49}$ maintained "that ataxia may be caused by a unilateral or a bilateral frontal lobe even in the absence of signs of increased intracranial pressure seems to admit of no contradiction" (p554). Hence the term "frontal ataxia" became popular. De Ajuriaguerra $\mathrm{et}_{\mathrm{al}} \mathrm{l}^{53}$ conceded that GA may be a sign of frontal involvement, though denied that it was apraxic in nature. On the other hand, Hartmann ${ }^{54}$ and Kleist ${ }^{6}$ conceived that the GA movement disorders be a form of true apraxia, due to lesion of a specific frontal centre devoted to deploying attention to negotiate gait or to the planning of trunk and lower limb movements, respectively. Crigel and Arseni ${ }^{55}$ studied 165 patients with either unilateral or bilateral frontal damage, $59(36 \%)$ of whom presented with gait disorganisation. They argued that the walking disturbances due to frontal apraxia or cerebellar ataxia could be differentiated from one another (see also table 2 in Meyer and Barron ${ }^{23}$ ). The concept of GA met with significant agreement ${ }^{12} 1922282956-62$ and is currently listed among the direct signs of frontal lobe damage (Adams et $a l^{73}$ pp 121-122; Kurlan et al ${ }^{64}$ ).

The precise localisation of GA within the frontal lobes remains elusive. Reviews of the early literature showed that most cases of GA involved tumours encroaching on or compressing the medial aspects of the frontal cortex bilaterally. ${ }^{93}$ However, the mapping of the symptoms onto the damage caused by a tumour is far from adequate.

Cases have also been reported of GA after vascular lesions, which should allow for a more precise localisation than allowed by tumours. ${ }^{6} 19232528576566$ Taken together this literature confirms that lesions to the medial walls of the frontal lobes are very likely to be responsible for the appearance of GA. In particular, the lesions found in these patients lay within the territory of the anterior cerebral arteries and softened the first frontal gyrus or the gyrus cinguli, with or without involving the corpus callosum. However, the lesions in these patients were either too large or not analysed in sufficient detail to allow firm conclusions about the precise identification of the structure the lesion of which may be responsible for GA. Moreover, although the clinical syndrome had been recognised long before, ${ }^{35}$ most reports of GA relied on a welter of signs never assembled in a formal diagnostic tool.

In this paper we report the case of a patient who was affected by a bilateral infarction of a portion of the anterior cerebral artery territory. The patient showed a clear GA, which was formally investigated with a new and standardised test (Della Sala et al, unpublished data). An unusual anomaly of the anterior cerebral artery system of the patient caused his stroke to affect only the first frontal gyri of both hemispheres. This allowed us to better delineate the boundaries of the lesion sufficient and necessary to give rise to GA.

\section{CASE REPORT}

The patient was a right handed (score 12/12 on the handedness Edinburgh inventory ${ }^{67}$ ) retired man with 6 years of formal education. He was 64 years old when he was admitted to the third neurological ward of the University of Milan because of a bilateral stroke in the anterior cerebral arteries system.

\section{Clinical picture}

Two days after admission, He showed a spastic paraplegia with bilateral sign of pyramidal impairment, coupled with severe hypophonia. Neurological examination disclosed also the presence of plantal grasp, of bilateral "tonic grasping", ${ }^{68}$ instances of groping ("magnetic apraxia" ${ }^{69}$ ) particularly with his right hand, and frontal release signs, such as bilateral palmomental and snout reflexes. ${ }^{70} \mathrm{He}$ also presented with motor and verbal inertia. ${ }^{71} 72$

One month after the onset, the patient was able to walk with two crutches.

Five months later his muscle stretch reflexes were still hyperactive in the lower limbs, although only minimal strength impairment was noticeable at the neurological examination. He had considerable difficulty in stopping walking on command and his gait, tentative and uncertain, was hampered by hesitation; in Liepmann's ${ }^{73}$ terminology, he seemed to have lost the "Virtuosität" of the normal gait.

Fourteen months after the patient's stroke, the neurological examination disclosed only a minimal strength deficit on the right side. His walking remained very clumsy. He could not imitate foot/leg movements performed by the examiner (for example, draw a circle with the leg extended while seated, or trace a cross on the floor with either foot).

\section{Neuroradiology}

A series of MRIs and a digital subtraction angiography disclosed a particular anomaly in the patient's anterior cerebral artery system, which supplies the medial surfaces of the frontal lobes. There are no right and left anterior cerebral arteries. His anterior vascular system is characterised by the presence of three main azygous-like trunks, one anterior, one middle, and one posterior, each one of which divides into a left and a right branch. From this vascular distribution derives the rare event that small symmetric areas of the medial surfaces of the right and left hemispheres are supplied by the same single artery. The patient had an occlusion of the middle trunk just before its partition, which gave rise to a stroke damaging symmetric portions of the medial walls of both of his frontal lobes. The lesion involved the superior frontal convolution (F1) of both hemispheres, sparing the polar regions, as well as the cingulate and the corpus callosum. In particular, it involved the supplementary motor areas (Brodmann's area 6) of both sides (figs 1, 2, and 3).

\section{General neuropsychological assessment}

The patients neuropsychological assessment has been detailed elsewhere. ${ }^{74}$ In brief, he was fully oriented and cooperative, was not aphasic, and did not show any impairment in visual perception. His scores on tests assessing general intelligence and different aspects of memory functions were all within the normal range. When first assessed, 2 months after onset, he performed poorly on some tests assessing executive functions, such as phonological fluency, reversal learning, or selective attention, which have all been shown to be sensitive to frontal lobe damage. ${ }^{75}$ However, 14 months after onset his psychometric profile was entirely within the limits of normality. He also showed several instances of utilisation behaviour ${ }^{76}$ and grasp reflex, which were still persistent at this time.

\section{Apraxia assessment}

\section{Imitation of intransitive gestures}

The test devised by De Renzi $e a l^{78}$ was employed. This is a 24 item imitation test consisting of half meaningful and half meaningless movements, half requiring the patient to hold a posture, and half the execution of a motor sequence. The score for each item ranges from 3 to 1 depending on whether the performance is flawless on the first, second, or third attempt. A score of zero is given when the performance is unsatisfactory all three times. Therefore the total score ranges from 0 to 72. Individual scores are age and education adjusted. The cut off point (53) corresponds to the worst score found in a group of 187 controls $^{79}$ and represents the $95 \%$ outer tolerance limit of the normal population. 

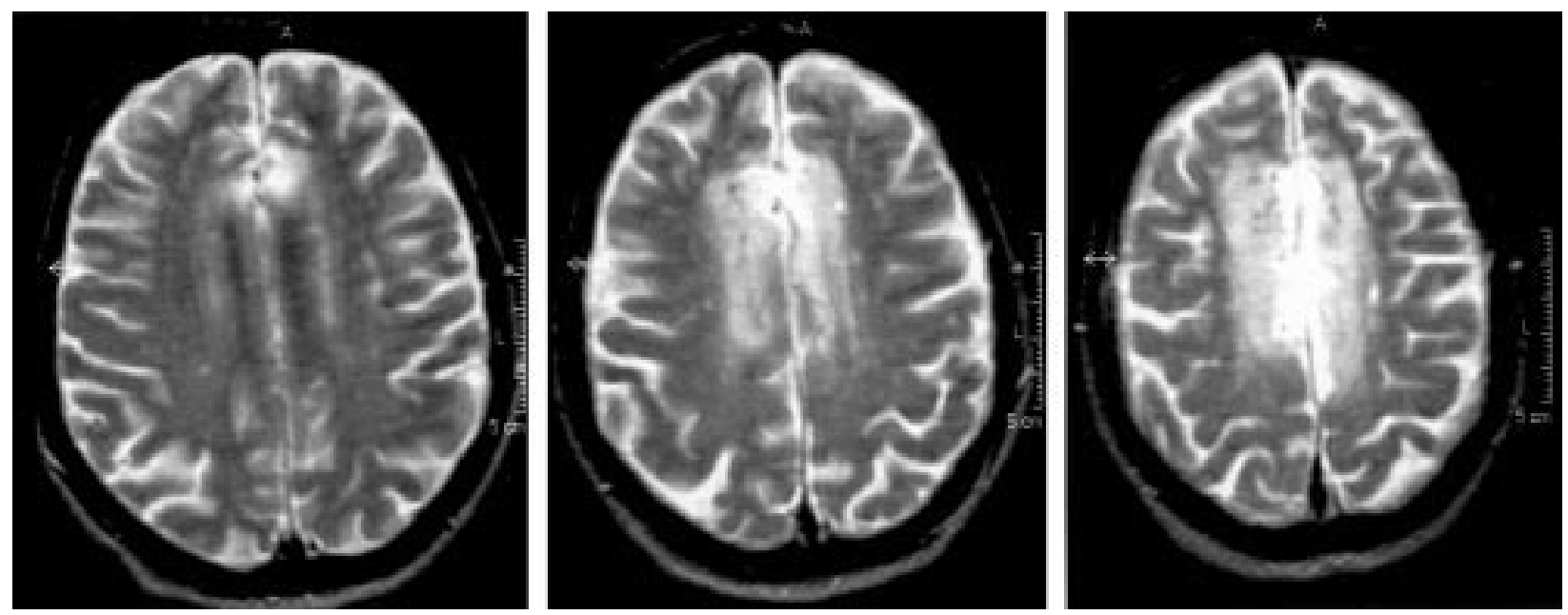

Figure 1 The patient's MRI T2 axial scans showing the lesion encroaching upon the superior frontal convolutions and centred on the SMA bilaterally.

\section{Actual use of objects}

The test described by De Renzi and Lucchelli $^{68}$ was used. Twenty objects of common use were presented one at a time to the patient. He was asked to demonstrate their use by carrying out a series of common, complex actions (for example a candle, a candlestick, and a matchbox were laid on the table and the patient was asked to light the candle). Scoring followed the published norms, score ranges from 0 to 120, cut off score is 60 (worst observed score in normal controls).

\section{Face apraxia}

Two tests assessing the imitation of the upper and the lower face movements respectively were used..$^{80}$ T1 The upper face apraxia test included nine items (for example, "Close your eyes", "Look down"), and the lower face apraxia test was made up of 29 items (for example, "Show your teeth", "Blow"). Items were scored as pass or fail according to a set of rules derived from previous authors' attempts to define errors in facial apraxia. ${ }^{82}{ }^{83}$ For both the upper and lower face tests, scoring procedures based on the rank order score were employed. The total score ranges from a worst of zero to a best score of 45.0 in the upper face apraxia test and to a best of 435.0 in the lower face apraxia test. Individual scores are age and education adjusted. Cut off scores, corresponding to the outer tolerance limit of the score distribution of 182 healthy volunteers $^{80}{ }^{81}$ are 38 and 400 for upper and lower face tests respectively.
The patient performed within the normal range on all tests assessing ideomotor, object utilisation, and upper and lower face apraxia. His scores are given in table 1.

\section{Gait apraxia}

The patient presented with difficulties in sitting on or standing from a chair on command. He had difficulty lying supine on the examining bed and could not roll over. These difficulties were also overt in his daily life. Indeed, his wife confirmed that he needed her assistance to go to bed and to rise from it. His walking was hesitant and at times he persevered with individual components of a movement sequence. He was well aware of these difficulties and understood what he was requested to do, although he upheld that he no longer knew how to perform these movements. These problems were initially traced back to his motor inertia and central paraplegia. However, these difficulties continued after the rapid recovery from his motor deficits (probably due to perilesional oedema) was almost complete. Indeed, the improvement of motor functions made it clear that he also had problems in starting to walk, in stopping going forward, let alone in trying to walk backwards. These deficits were so severe as to be far beyond the possible sequelae of some elementary neurological deficits. He did not show any cerebellar or parkinsonian signs or symptoms. Pseudobulbar palsy was highly unlikely as he was not dysphagic nor dysarthric, showed no signs of diffuse cognitive deterioration, and the MRI disclosed no signs of subcortical lacunae.
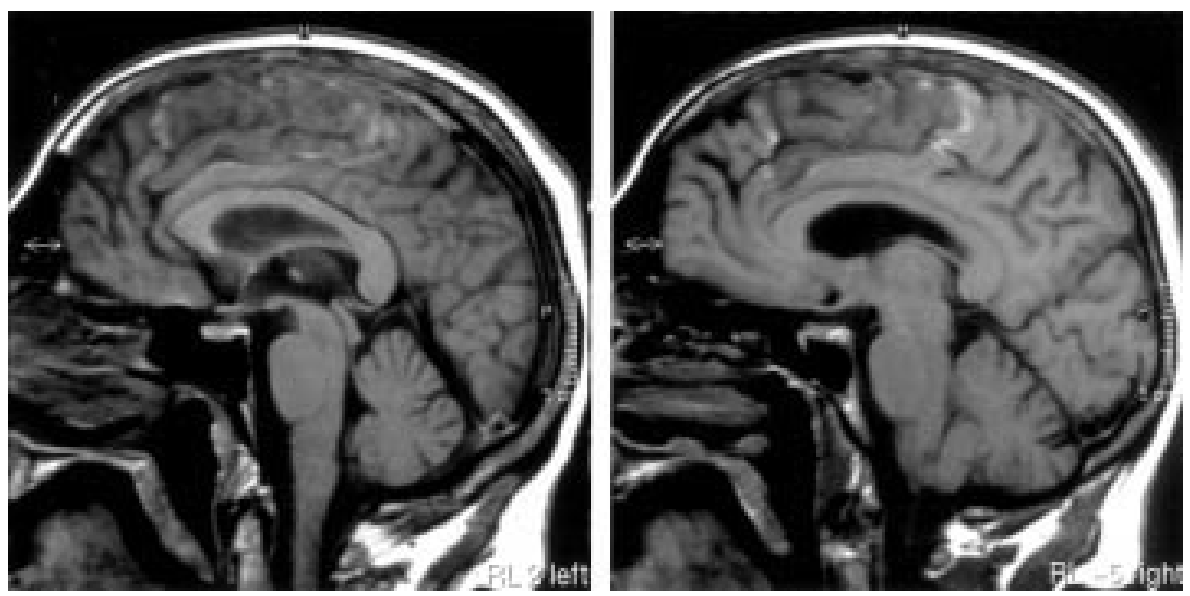

Figure 2 The patient's MRI T1 parasagittal scans. Left: parasagittal scan $2 \mathrm{~mm}$ off the midline. Right: parasagittal scan $5 \mathrm{~mm}$ off the midline. 

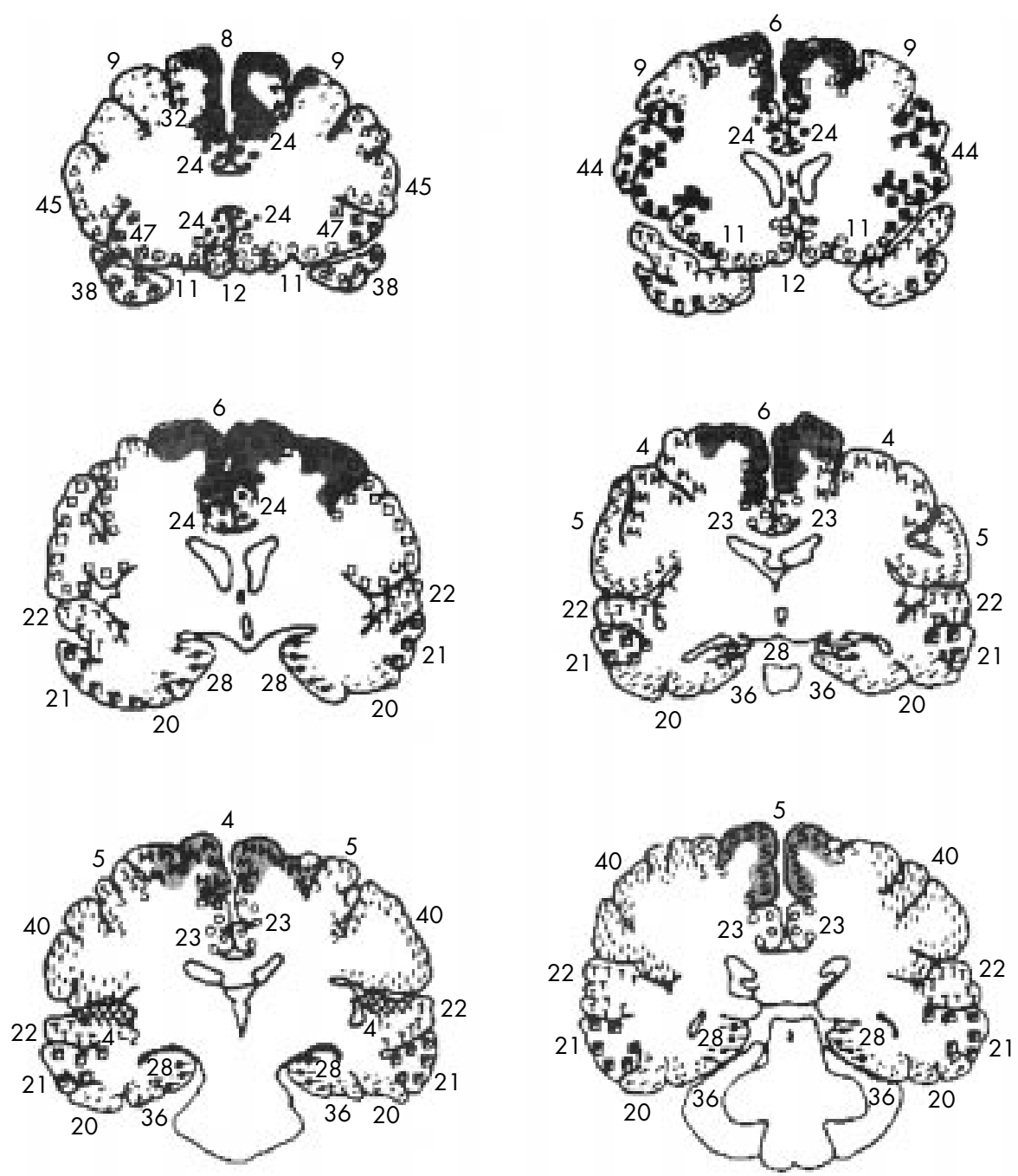

Figure 3 The patient's MRI coronal scans were mapped onto standard templates following a standard procedure. ${ }^{116}$ Numbers refer to Brodmann's areas. The lesions affected the medial aspects of the frontal lobes bilaterally. In particular, the supplementary motor areas were damaged, whereas the cingulum and the corpus callosum were spared.

His steps were irregular and hampered by several inappropriate and incongruous movements; he also showed gait ignition failures and some instability in maintaining his upright stance. On the other hand he kept his trunk upright while walking and arm swinging was preserved. The suspicion of GA was raised and formally tested.

His GA was formally assessed 14 months after his stroke. The GA test includes 70 items (plus six items used as run in examples) devised to assess trunk and lower limb movements and gait (Della Sala, Spinnler, and Venneri, unpublished data).

Table 1 The patient's performance in tests assessing ideomotor, utilisation, and facial praxis abilities 14 months post-onset

\begin{tabular}{llll}
\hline Test & $\begin{array}{l}\text { Patient } \\
\text { score }\end{array}$ & $\begin{array}{l}\text { Scale score } \\
\text { range }\end{array}$ & $\begin{array}{l}\text { Cut off } \\
\text { score }\end{array}$ \\
\hline Ideomotor apraxia right hand* $^{*}$ & 72 & $0-72$ & 53 \\
Ideomotor apraxia left hand* & 65 & $0-72$ & 53 \\
Utilisation apraxia $\dagger$ & 120 & $0-120$ & 60 \\
Upper face apraxia & 41 & $0-45$ & 38 \\
Lower face apraxia $\neq$ & 433 & $0-435$ & 400 \\
\hline
\end{tabular}

${ }^{*}$ De Renzi et $a^{88} ; \nmid$ De Renzi and Lucchelli; ${ }^{68} ; \ddagger$ Bizzozero et $a^{80} ;$ Della Sala et al. ${ }^{81}$
The items included in the GA test have been grouped according to the anatomical district tested. The trunk component of the test includes 22 items (for example, "Anterior flexion of trunk", "Turn from prone to supine"). The walking component includes 20 items (for example, "Walk on the spot", "Walk to the right whilst facing forward") and 28 items form the lower limbs component (for example, "Slide left leg backward while seated", "Trace a clockwise circle on the floor using your right foot").

Each item was demonstrated and orally described by the examiner. The patient had to respond by imitation immediately after presentation. Items were scored as pass or fail according to a set of rules derived from previous studies of apraxia ${ }^{80}$ Performance was rated as hit score: the higher the score the better the performance. The GA test total score therefore ranges from zero to 70 and results from the sum of scores to the three separate components. Items are failed when the general organisation of the movements is relatively preserved, but their execution lacks dexterity (for example, legs over or under lifted, stepping irregular by size, speed or direction). An item is also failed when the performance is clearly inaccurate, (for example, the patient crossed his legs while attempting to walk), or accompanied by ineffectual, parasitic movements.

Cut off values were determined by assessing the performance of 182 healthy controls (Della Sala, Spinnler, and 
Table 2 The patient's performance in the three components of the tests assessing GA 14 months after onset

\begin{tabular}{lllll}
\hline Test & $\begin{array}{l}\text { Patient } \\
\text { score }\end{array}$ & $\begin{array}{l}\text { Scale score } \\
\text { range }\end{array}$ & $\begin{array}{l}\text { Cut off } \\
\text { score }\end{array}$ & $\begin{array}{l}\text { Age matched } \\
\text { controls (SD) }\end{array}$ \\
\hline Trunk & 11 & $0-22$ & 20 & 22 \\
Walking & 10 & $0-20$ & 17 & $19.9(0.4)$ \\
Lower limbs & 5 & $0-28$ & 26 & $27.7(0.6)$ \\
GA total score & 26 & $0-70$ & 65 & $69.5(0.7)$ \\
\hline
\end{tabular}

Venneri, unpublished data). Most controls performed at ceiling in all the three components of the test. The score corresponding to the inner tolerance limit of the normal distribution was chosen as the cut off point in all tests.

The patient scored poorly on all three components of the task. For example, he failed to turn his head towards the left, or to bend his trunk forward, he proved unable to turn from prone to supine on the bed. He could not mime marching on the spot nor marching sidewise to the left or to the right. He failed all attempts when asked to pretend to extinguish a cigarette while seated, to kick an imaginary ball, or to wipe his feet on a mat.

His scores together with score ranges, cut off scores derived from norms, and the mean scores achieved by 26 controls aged between 60 and 69 in each component of the test, are reported in table 2 .

\section{DISCUSSION}

\section{Gait apraxia as a clinical entity}

All purposeful movements involving trunk and legs, including walking, contribute to very complex performances. Not only do they need the cooperation and coordination of several muscular districts, but they also call for perfect timing and sequencing of events, which, once learnt, become a semiautomatic performance.

Several neurological diseases and psychiatric conditions can impair this complex, skilful performance. The impairment of locomotion not accountable for by any alternative cause, coupled with cerebral lesions encroaching upon areas known to be involved in its accomplishment, should be considered GA. Gait apraxia is defined as the loss of monitoring of the automatic implementation of gait mechanisms.

Gait apraxia has a long history. However, its precise nature and localisation are still defiant of exact identification. The case of the patient reported in this paper helps refine the syndrome, thanks to the standardised tests employed, and allows for a more accurate topographical definition of the responsible brain lesion, because of the unusual anomaly of his anterior cerebral arteries system.

The patient never showed any problems in negotiating difficult walks (for example, mountain routes) before his stroke. We interpreted his clinical picture as apraxic because of the lack of overt elementary motor, ataxic, or psychiatric deficits. He presented with disturbances in all the domains of GA acknowledged by Zingerle ${ }^{28}$ and by Nutt et $a l^{20}$ as the core symptoms of "frontal gait disorder" ${ }^{20}$ - that is, walking disturbances, disequilibrium, loss of postural reflexes, counterproductive parasitic movements. He also manifested ignition failure with his feet glued to the floor, ${ }^{12}$ his walk was stiff and graceless and characterised by difficulty in stopping and turning. This paramount inability to halt one's own gait was described by $\operatorname{Brun}^{58}$ (case $\mathrm{H}$ ) as being similar to that of an automaton ("glich völlig einer lokomotorischen Maschine", translation: he was akin to an automaton, p 215). Moreover, the patient failed to reproduce by imitation or on verbal command meaningful gestures (for example, a cross, a circle) with either his leg or foot, a sign seen by other authors in patients affected by GA. ${ }^{19}$

\section{Anatomical remarks}

Table 3 summarises the 49 cases we could glean from the literature reporting the localisation of GA. In 45 of these cases the localisation was precise enough to contribute to our discussion. Different authors used different labels to describe similar sets of GA signs. Moreover, they chose to emphasise different aspects of the syndrome, often according to their theoretical frame of reference. The localisation is reported as given by the authors*.

From the analysis of table 3 it is possible to deduce that GA is not a rare entity and can be due to different aetiologies. However, cases of "pure" GA are scant. With few exceptions (for example, case $\mathrm{K}^{57}$ ) the lesion damaged the precentral aspects of the frontal lobes, with or without involvement of the genu of the corpus callosum. In 24 cases out of 45 in which the localisation was possible the lesion was bilateral. When the lesion was reported as unilateral, there seems to be some evidence for a left asymmetry ( 13 left cases versus eight right).

Indeed, Lange ${ }^{27}$ stated that "certainly frontal lobe lesions play a key role in GA, yet it would be premature to maintain that left frontal lobe lesions are more frequently associated with GA than the right ones, and which region is more important $^{\prime \prime * *}$. Kleist ${ }^{26}$ came to the same conclusion on the basis of his review of the literature and stated that the lesion responsible for GA is located "at the foot of $\mathrm{Fl}, \ldots$; the role of the corpus callosum is uncertain".

Scrutiny of the descriptions of the cases reported in table 3 (tumours and abscesses) discloses that the medial aspects of the frontal lobes are involved in most of them. Accordingly, Frazier $^{49}$ reported that $49 \%$ of 105 cases of patients with a frontal tumour upon whom he operated showed one or more "pseudocerebellar" signs of "frontal ataxia" (p 548). He also maintained that in most cases the lesions occupied the superior aspects of the frontal lobes, whereas none encroached upon the olfactory groove or the frontal poles. However, the growth of malignant tumours permits only flawed localisation.

Stroke and injury cases (table 3 ) should allow for a better relation between symptoms and site of lesion. Unfortunately, in several cases, the information available is too gross to attempt any fine grained localisation. Only three cases describe with some certainty a circumscribed lesion of the medial aspects of $\mathrm{Fl}$ ( case $\mathrm{K}^{8}$; case $\mathrm{JS}^{56}$; case $\mathrm{HP}^{19}$ ). In some further cases the corpus callosum was damaged, pointing to medial lesion ( case $^{57}$; case $1^{66}$ ). Moreover, von Monakow ${ }^{18}$ (pp 547-52) reported on the case of patient Koch affected by a post traumatic cyst invading the whole left frontal lobe but F1. This woman did not show GA, upholding the view that GA be associated with F1 lesions.

Gait apraxia has been mentioned also in three cases affected by Pick's disease (case Zorn ${ }^{8}{ }^{27}$; case $\mathrm{AC}^{25}$ ), one affected by notdefined brain atrophy (case Gloor ${ }^{8}$ ), and two with neurosyphilis (case $\mathrm{LS}^{84}$; case No $2^{23}$ ). All these cases had a predominantly frontal atrophy, further emphasising the association between GA and frontal damage. Moreover, Rossor $e t a l^{37}$ described GA in two demented patients reporting also PET data showing clear medial frontal hypometabolism in both patients.

Lastly, some indirect evidence supporting the frontomedial hypothesis of GA comes from the finding that gait abnormalities associated with normal pressure hydrocephalus have been

*The six patients with gait ignition failure reported by Atchison et $a l^{12}$ are not listed in table 3 because the authors explicitly maintain that the symptom they describe should be differentiated from GA. However, the authors acknowledged that gait ignition failure is due to frontal damage. We see no reasons to keep it separate from other manifestations of GA. **"Sicherlich spielt auch fuer sie das Stirnhirn eine wesentliche Rolle, ob das linke vorwiegend und in welchen besonderen Anteilen, läßt sich noch nicht näher feststellen". ${ }^{27}$ 
Table 3 Localisation of lesions of patients presenting with signs compatible with the diagnosis of GA gleaned from the literature and subdivided according to aetiology

\begin{tabular}{|c|c|c|c|c|}
\hline Author(s), year & Case & Age & Sex & Localisation \\
\hline \multicolumn{5}{|l|}{ Traumas: } \\
\hline \multirow[t]{2}{*}{ Feuchtwanger $1923^{110}$} & A.Li & 32 & M & Metal splinter in the $L$ and $R F$ \\
\hline & MK & 20 & M & Bullet in the R F \\
\hline Kleist $1934^{8}$ & K & NR & M & Bullet through $L$ and $R$ areas $6+g C C$ \\
\hline \multicolumn{5}{|l|}{ Tumours and abscesses: } \\
\hline \multirow[t]{4}{*}{ Bruns $1892^{14}$} & 1 & NR & NR & "Sarcoma" $L$ and $R$ medial $F$ \\
\hline & II & 54 & $M$ & Large subdural haematoma L F \\
\hline & III & 36 & $M$ & "Sarcoma" L F2. \\
\hline & IV & 60 & $M$ & Glioma R F2, F3 \\
\hline van Vleuten $1907^{97}$ & $\mathrm{AL}$ & 55 & $M$ & "Sarcoma" $\mathrm{L}$ gCC $+\mathrm{L} F 1+\mathrm{L}$ cingulum \\
\hline Hartmann $1907^{54}$ & WF & 57 & $M$ & Glioma $\mathrm{gCC}+\mathrm{L}$ and $\mathrm{R}+$ cingulum \\
\hline Vincent $1911^{46}$ & Th & 54 & W & Glioma RF \\
\hline Brun $1921^{58}$ & $\mathrm{H}$ & 25 & $M$ & Glioma $\mathrm{R}$ medial F+CC \\
\hline \multirow[t]{2}{*}{ von Monakov $1914^{18}$} & $\mathrm{E}$ & 59 & W & Glioma $\mathrm{L}$ medial $\mathrm{F} 1+\mathrm{gCC}+\mathrm{R}$ cingulum \\
\hline & W & 58 & W & Metastases medial $\mathrm{L}$ and $\mathrm{R} F+\mathrm{gCC}$ \\
\hline Dimitz and Schilder $1922^{60}$ & MW & 38 & W & Glioma L and R F1 F3 polar+gCC \\
\hline \multirow[t]{2}{*}{ Pötzl $1924^{29}$} & $\mathrm{HK}$ & 18 & W & Abscess R F polar \\
\hline & & & $M$ & Glioma R F polar \\
\hline Marie et al 1924 ${ }^{111}$ & $\mathrm{MH}$ & 56 & M & Glioma R F1, F2 \\
\hline Gerstmann and Schilder $1926^{22}$ & $\mathrm{FW}$ & 56 & M & Glioma L medial F \\
\hline Klein $1928^{44}$ & $J G$ & 52 & $M$ & Glioma R F+basal ganglia \\
\hline Adie and Critchley $1927^{112}$ & $\mathrm{AL}$ & 54 & $M$ & Glioma R Fl \\
\hline \multirow{2}{*}{ van Bogaert and Martin $1929^{2}$} & $\mathrm{RB}$ & 47 & W & Abscess LF1, F2 \\
\hline & MK & 34 & W & Glioma L F orbitopolar \\
\hline Sittig $1929^{1}$ & & 39 & $\mathrm{~F}$ & Tumour around CC \\
\hline \multirow[t]{2}{*}{ Kleist $1934^{8}$} & $M$ & NR & NR & Glioma R F1 (area 6), L Fl+CC \\
\hline & $\mathrm{S}$ & NR & NR & Glioma $\mathrm{L}$ and $\mathrm{R} F \mathrm{~F}+\mathrm{gCC}$ \\
\hline \multirow[t]{2}{*}{ Bell, $1934^{113}$} & LD & 53 & W & Glioma R F+gCC \\
\hline & $\mathrm{CP}$ & 31 & W & Granuloma anterior CC+hydrocephalus \\
\hline Frazier $1936^{49}$ & 5 & 4 & $M$ & Fibroblastoma of the falx $L$ and $R$ \\
\hline Petrovici $1968^{25}$ & MA & 28 & M & Astrocitoma L F* \\
\hline \multicolumn{5}{|l|}{ Strokes: } \\
\hline Liepmann 1900 (quoted by Lange 1936 $6^{27}$ ) & $\mathrm{T}$ & 48 & M & $L^{*}$ \\
\hline Abraham $1907^{56}$; Brun $1921^{58}$ & JS & 58 & M & $\mathrm{L}: \mathrm{TPO}+\mathrm{F} 1+\mathrm{CC}$ \\
\hline Westphal $1907^{15}$ & NR & 58 & $M$ & $\mathrm{R}: \mathrm{F}$ and $\mathrm{L}: \mathrm{O}+\mathrm{Th}$ \\
\hline Kleist $1907^{6}$ & NR & 44 & M & $L$ and $R: F^{*}$ \\
\hline \multirow{2}{*}{ Kroll $1910^{57}$} & $\mathrm{~K}$ & 49 & M & L: supramarginal and angular gyri. \\
\hline & $\mathrm{T}$ & 45 & M & $\mathrm{L}: \mathrm{F} 2+$ supramarginal girus+gCC \\
\hline Bonhöffer $1914^{19}$ & HP & 51 & M & $\mathrm{L}: \mathrm{Fl}, \mathrm{F} 2+$ orbital+CC \\
\hline Mingazzini and Ciarla $1920^{66}$ & 1 & 60 & M & $\mathrm{R}$ : internal capsule $+\mathrm{L}$ gCC \\
\hline Schuster and Pinéas $1926^{99}$ & $M L$ & 70 & W & $L^{*}$ \\
\hline Maas and Sittig $1929^{114}$ & $A R$ & 70 & W & $L$ and $R$.* \\
\hline Zingerle $1934^{28}$ & MP & 61 & $M$ & L and R.* \\
\hline Ethelberg $1951^{115}$ & 27 & 59 & W & ACA atherosclerosis (angiography) $L>R+$ hydrocephalus \\
\hline \multirow[t]{3}{*}{ Meyer and Barron $1960^{23}$} & 1 & 71 & $M$ & Anterior $L$ and $R^{*}$ \\
\hline & 4 & 49 & $M$ & $A C A L$ and $R^{*}$ \\
\hline & 7 & 59 & $M$ & $A C A L$ and $R$.* \\
\hline \multirow[t]{2}{*}{ Petrovici $1968^{25}$} & IF & 70 & W & $A C A L^{*}$ \\
\hline & $M M$ & 63 & $M$ & Multiple infarcts $L$ and $R^{*}$ \\
\hline \multirow[t]{3}{*}{ Nutt et al $1993^{20}$} & NR & 83 & $M$ & Multiple strokes* \\
\hline & NR & 68 & M & Periventricular vascular disease* \\
\hline & NR & 81 & $M$ & NR \\
\hline
\end{tabular}

*Postmortem not available; ACA, anterior cerebral artery; CBD, corticobasal degeneration; CC, corpus callosum; F, frontal; F1, F2, F3, first, second, third frontal gyrus; gCC, genu corpus callosum; L, left; R, right; TPO, temporo-parietal-occipital; NR, not reported.

traced back to the compression of the areas adjacent to the frontal horns of the lateral ventricles. ${ }^{85-87}$

\section{Neuropsychological remarks}

Our patient showed no deficits in any other praxis domain. His performance on tests assessing upper limb ideomotor apraxia, utilisation apraxia, and facial apraxia was well above the threshold of normality. This finding points to a dissociation between GA and other kinds of apraxia. Durwen et al ${ }^{41}$ examined the case of patient IL who had a stroke in the territory of the middle cerebral artery, and presented with oral and ideomotor apraxia but not gait apraxia, a mirror picture of that presented by our patient. They argued that for GA to emerge a lesion within the territory of the anterior cerebral artery is necessary. Moreover, several authors ${ }^{38-40}$ have argued for a relative preservation of trunk movements compared with ideomotor apraxia of the upper limbs, after parietal lesions (see further discussion in Howes ${ }^{42}$ and Poeck et $a l^{43}$ ). Taken together, these findings point to a dissociation between GA associated with frontomedial lesions and ideomotor apraxia associated with (left) parietal lesions.

Indeed, lesions of frontomedial regions, in particular of the supplementary motor areas do not elicit ideomotor apraxia ${ }^{88}$ (for reviews see Laiacona et $a^{89}$ andMarchetti and Della Sala ${ }^{90}$ ). Watson $e t ~ a l^{91}$ reported the only two cases of bilateral apraxia after a lesion in the left supplementary motor area of which we are aware. Only one of them (case 1) was assessed at some length. However, the patient of Watson et al showed an asymmetry in performance: 13 months after the lesion, his apraxia was present only on the left hand, ${ }^{92}$ which leaves us with the suspicion that this patient's apraxia might be due to a lesion of the corpus callosum. The other patient with a supplementary 
motor lesion studied in some detail had a crossed apraxia, ${ }^{90}$ and therefore the rarity of her praxis organisation should be considered with some caution.

A careful analysis of case reports describing patients with anarchic hand and lesions to the supplementary motor areas $^{93}$ showed that ideomotor apraxia is extremely rare, if at all present. On the contrary, fleeting comments concerning difficulty that patients with anarchic hand may have controlling their gait or leg movements abound. ${ }^{90}{ }^{93}$ These problems have been sometimes labelled (bilateral) "alien foot", ${ }^{94-96}$ although their resemblance to GA symptoms is staggering. The opposite situation is also encountered: patients are reported showing a paramount GA who also presented with clear episodes of anarchic hand behaviour. For example, Van Vleuten ${ }^{97}$ related that his patient AL (table 3) while being examined could not refrain from compulsorily unbuttoning his shirt with his left hand even when instructed not to do so. Kleist $^{6}$ (table 3 ) also described a patient with multiple frontal strokes who was unable to inhibit endless spontaneous movements of his right hand which interfered with the actions he was requested to carry out. Our patient had a bilateral supplementary motor area lesion and, besides his overt GA, presented with a clear utilisation behaviour syndrome, which has been interpreted as a double anarchic hand. ${ }^{74}$

In summary, lesions to one supplementary motor area could give rise to contralateral anarchic hand and contralateral GA (which, however, will be clinically hard to detect as such given that the nature of the actions performed require bilateral cooperation). Bilateral lesions to the same areas might produce utilisation behaviour and a full blown GA. Moreover, lesions to the medial areas of the frontal lobes are also likely to be associated with grasp reflex (tonische Perseveration des Greifen $^{16}$; Zwangsgreifen ${ }^{98}$; Nachgreifen ${ }^{68}{ }^{99}$ ) which our patient showed from onset and throughout the follow up. On the other hand, ideomotor apraxia would be seen mainly after left parietal lesions. ${ }^{100}$

The problem remains of the possible compensatory mechanism from the intact hemisphere in unilateral cases. Follow up studies of GA are rare. Our patient was still severely apraxic over a year after his stroke. The only other case with a longitudinal follow up we could cull from the literature is that of patient FZ described by Zingerle. ${ }^{28}$ He was a 79 year old man, with alcoholism, arsenic poisoning, and possibly a right hemispheric stroke, whose severe GA improved considerably after a few months. The possibility that a unilateral GA might get better, whereas a bilateral one would not should remain speculative at this stage.

\section{A cognitive interpretation}

The puzzle of GA interpretation has haunted early authors and has yet to be resolved.$^{20}$ Hartmann ${ }^{54}$ maintained that the frontal lobes contain a "Merkzentrum für die höhere Koordination der Bewegungsbilder" (an attention centre for the coordination of movement representations). Gerstmann and Schilder ${ }^{22}$ and Klein $^{44}$ revamped the concept of gliedkinetische Apraxie ${ }^{15}$ (also known as "innervatory" "cortical"17 "melo-kinetic"101 or "limb-kinetic", ${ }^{102}{ }^{103}$ ) to account for GA. Bonhöffer, ${ }^{19}$ Denny Brown, ${ }^{9}$ and Meyer and Barron ${ }^{23}$ claimed it to be due to a contralateral frontal lesion. Kleist ${ }^{8}$ (p 952, table 3) maintained that area 6 contained a centre for the organisation of complex movements performed with trunk and lower limbs, such as dancing, hopping, or swapping the bearing of a walk. He also argued that this centre was non-lateralised (see also Liepmann ${ }^{5}$ pp 97-9). The link between supplementary motor areas and innervatory patterns has been recently advocated by Rothi et al ${ }^{104}{ }^{105}$ though referring it to a mechanism necessary to code any gesture output lexicon into a space-time supramodal plan.

Our patient shows GA coupled with utilisation behaviour. ${ }^{74}$ We held his bilateral supplementary motor areas lesion responsible for both motor disturbances. Among their other functions ${ }^{106}$ the two supplementary motor areas would supervise two apparently heterogeneous tasks-namely, locomotion and context independent utilisation. We support the hypothesis that bilateral GA, as found in our patient, should be considered a "motor" rather than an "ideomotor" apraxia. In fact, his deficits were present in all attempts independent of the context and not only on imitation.

Finally, we contend that GA has its own specificity, the diagnosis of which is possible only after having excluded other possible causes of gait disturbances. To account for this specificity we capitalise on a hypothesis put forward by Pötzl. ${ }^{29}$ He deemed that the change of the locomotor technique from four to two footed upright position, was paralleled by the phylogenetic enlargement of the frontal cortex (Fuster ${ }^{107} \mathrm{pp}$ 174-81). He also reckoned that the coordination of gait in humans piggybacked on this process, and the frontal lobes took it over. This could have given rise to an anatomical segregation of praxis abilities. Those devoted to hand movements and the skilful use of tools would be centred on the left parietal lobe. Those required for the complexity of the mostly automatic gait movements would be carried out by the frontal lobes, in particular by the supplementary motor areas, which in this frame would serve a self monitoring function. ${ }^{108}$

\section{ACKNOWLEDGEMENTS}

We thank Reiner Kashel who helped us by tracing some of the early German papers and Ian Deregowski who helped us to translate the paper by Crigel and Arseni from Russian. We are also grateful to Edoardo Boccardi who performed the angiography and helped us interpret the MRI, to Alessandra Maietti who helped us map them onto the templates, and to Cristina Motto, under whose care our patient was. Angela Bartolo helped us organise the early literature.

\section{Authors' affiliations}

S Della Sala, Neuropsychology Research Group, Department of Psychology, University of Aberdeen, UK

A Francescani, H Spinnler, Third Neurology Ward, Department of Medicine, Surgery, and Dentistry, University of Milan, S Paolo Hospital, Milan, Italy

\section{REFERENCES}

1 Sittig O. Über Apraxie (mit Filmvorführung). Zentralblatt der Neurologie und Psychiatrie 1929;53:429-32.

2 van Bogaert L, Martin P. Sur deux signes du syndrome de déséquilibration frontale. L'apraxie de la marche et l'atonie statique. Encephale 1929:24:11-18.

3 Petren K. Über den Zusammenhang zwischen anatomisch bedingter and fractioneller Gangstörung (Besonders in der Form von trepidanter Abasie) im Greisenalter, 1. Archiv für Psychiatrie und Nervenkrankheiten $1901 ; 33: 818-71$

4 Petren K. Über den Zusammenhang zwischen anatomisch bedingter and fractioneller Gangstörung (Besonders in der farn von trepidander Abasie) im Greisenalter, 2. Archiv für Psychiatrie und Nervenkrankheiten 1902;34:444-89.

5 Liepmann H. Über Störungen des Handelns. Berlin: Karger, 1905.

6 Kleist K. Kortikale (innervatorische) Apraxie. Jahrbuch der Psychiatrie 1907:28:46-1 12.

7 Poppelreuter W. Die psychischen Schädingungen durch Kopfschuß im Kriege 1914-1916, vol. 1: Die Störungen der niederen und höheren Sehleistungen durch Verletzung des Okzipitalhirns. Leipzig: Voss, 1917 (English Translation by J Zihl.) Disturbances of lower and higher visual capacities caused by occipital damage, with special reference to the psychopathological, pedagogical, industrial, and social implication. Oxford: Oxford University Press, 1991.)

8 Kleist K. Gehirnpathologie, vornehmlich auf Grund der Kriegserfahrungen. Leipzig: Barth, 1934.

9 Denny-Brown D. The nature of apraxia. J Nerve Ment Dis 1958;1 26:9-32

10 Thomson PD, Marsden CD. Gait disorders of the subcortical arteriosclerotic encephalopathy: Binswanger's disease. Mov Disord 1987;2:1-8.

11 Fitzgerlard PM, Jankovic J. Lower body parkinsonism: evidence for vascular etiology. Mov Disord 1989;4:249-60.

12 Atchison PR, Thomson PD, Frackowiak RSJ, et al. The syndrome of gait ingition failure: a report of six cases. Mov Disord 1993;8:285-92.

13 Nothnagel H. Topische Diagnostik der Gehirnkrankheiten, Eine klinische Studie. Berlin: Hirschwald, 1879. 
14 Bruns L. Über Störungen des Gleichgewichtes bei Stirnhirntumoren. Disch Med Wochenschr 1892:18:138-40.

15 Westphal K. Über einen Fall von motorischer Apraxie. Allgemeine Zeitschrift für Psychiatrie 1907;64:452-9

16 Liepmann H. Apraxie. In: Brugsche H, ed. Ergebnisse der Gesamten Medizin. Berlin: Urban und Schwarzenberg, 1920;516-43.

17 Heilbronner K. Zur klinisch-psychologischen Untersuchungtechnik. Monatsschrift für Psychiatrie und Neurologie 1905;17:115-32.

18 von Monakow C. Die Lokalisation im Großhirn und der Abbau der Funkion durch corticale Herde. Wiesbaden: Bergmann, 1914.

19 Bonhöffer K. Klinischer und anatomischer Befund zur Lehre von der Apraxie und der motorischen Sprachbahn. Monatsschrift für Psychiatrie und Neurologie 1914;35:113-28.

20 Nutt JG, Marsden CD, Thomson PD. Human walking and higher-level gait disorders, particularly in the elderly. Neurology 1993;43:268-79.

21 Tyrrell PJ. Apraxia of gait of higher level gait disorders: review of two cases of progressive gait disturbance due to frontal lobe degeneration. $J$ $R$ Soc Med 1994:87:454-6

22 Gerstmann J, Schilder P. Über eine besondere Gangstörung bei Stirnhirnerkrankung. Wien Med Wochenschr 1926;76:97-102.

23 Mayer YS, Barron DW. Apraxia of gait: clinico-physiological study. Brain 1960:83:261-84

24 Sudarsky L, Ronthal M. Gait disorders among elderly patients: a survey study of 50 patients. Arch Neurol 1983;40:740-3.

25 Petrovici I. Apraxia of gait and trunk movements. J Neurol Sci 1968;7:229-43

26 Kleist K. Der Gang und der gegenwärtiger Stand der Apraxieforschung. Ergebnisse der Neurologie und Psychiatrie 1911;1:343-60.

27 Lange J. Agnosie und Apraxie. In: Bumke O, Föster O, eds. Handbuch der Neurologie: Allgemeine Neurologie: Grosshirn, Vegetatives Nervensystem, Körperbau und Kostitution. Berlin: Springer, 1936;807-960

28 Zingerle H. Ausfalls-Syndrom der frontalen Brücken-Kleinhirn-Bahnen (Tractus fronto-ponto-cerebellaris). Zeitschrift für die gesamte Psychiatrie une Neurologie 1934;149:737-64

29 Pötzl O. Über ein neuartiges Syndrome bei Hirnerkrankungen des Stirnhirnpoles (Neurologischer Bericht über einen der Elschnigschen Fälle von erfolgreich operiertem Stirnhirnabscess). Zeitschrift für die gesamte Psychiatrie une Neurologie 1924;91:147-182.

30 de Ajuriaguerra J, Hécaen $\mathrm{H}$. Le cortex cérébral. Ełude Neuropsychopathologique. Paris: Masson, 1960

31 Geschwind N, Damasio AR. Apraxia. In: Frederiks JAM, ed. Clinical neuropsychology. Amsterdam: Elsevier, 1985;423-32.

32 Poeck K. Clues to the nature of disruptions to limb apraxia. In: Roy EA ed. Neuropsychological studies of apraxia. Amsterdam: North-Holland, 1985;99-109.

33 De Renzi E. Apraxia. In: Boller F, Grafman J, eds. Handbook of neuropsychology. Amsterdam: Elsevier, 1989;245-63.

34 Marsden CD, Thompson PD. Toward a nosology of gait disorders: descriptive classification. In: Masdeu JC, Sudarsky L, Wolfson L, eds. Gait disorders of aging. Philadelphia: Lippinccott-Raven, 1997;135-57

35 Wernicke C. Lehrbuch der Gehirkrankheiten für Ärzte und Studirende. Kassel: Fischer, 1881

36 Oppenheim H. Zur Pathologie der Grossirhngeschwülste. Archiv für Psychiatrie und Nervenkrankheiten 1890;21:560-87, 705-45

37 Rossor MN, Tyrrell PJ, Warrington EK, et al. Progressive frontal gait disturbance with atypical Alzheimer's disease and corticobasal degeneration. J Neurol Neurosurg Psychiatry 1999;67:345-52.

38 Geschwind N. The apraxias: neural mechanisms of disorders of learned movement. American Scientist 1975;63:188-195.

39 Hanlon RE, Mattson D, Demery JA, et al. Axial movements are relatively preserved with respect to limb movements in aphasic patients. Cortex 1998;34:731-41.

40 Alexander MP, Baker E, Naeser MA, et al. Neuropsychological and neuroanatomical dimensions of ideomotor apraxia. Brain 1992;115:87-107.

41 Durwen HF, Reuter BM, Linke DB. Ein Fall von Apraxie end globaler Aphasie bei fehkender Apraxie für Bewegungen der Körperachse. Schweizer Archiv für Neurologie und Psychiatrie 1992;143:197-209.

42 Howes DH. Ideomotor apraxia: evidence for the preservation of axial commands. J Neurol Neurosurg Psychiatry 1988;51:593-8.

43 Poeck K, Lehmkuhl G, Willmes K. Axial movements in ideomotor apraxia. J Neurol Neurosurg Psychiatry 1982;45:1 125-9.

44 Klein R. Über frontale Störungen des Gehens und des Gesanges. Monatsschrift für Psychiatrie und Neurologie 1928:69:12-33.

45 Austregilo A, Borges-Fortes A. Syndrome de déséquilibre et ataxie frontale. Encephale 1936;31:1-14.

46 Vincent C. De quelques causes d'erreur dans le diagnostic des syndromes d'hypertension intracranienne et dans celui de la localisation des tumeurs cérébrales. Rev Neurol 1911:22:209-217.

47 Grant FC. Cerebellar symptoms produced by supratentorial tumors. Archives of Neurology and Psychiatry (Chicago) 1928;20:292-308.

48 Liepmann H. Das Krankheitsbild der Apraxie. Monatsschrift für Psychiatrie und Neurologie 1905;17:289-311.

49 Frazier $\mathrm{CH}$. Tumor involving the frontal lobe alone: a symptomatic survey of one hundred and five verified cases. Archives of Neurology and Psychiatry (Chicago) 1936;35:525-71.

50 Puusepp L. Die Tumoren des Gehirns. Tartu: Dorpat, 1927.

51 Hare CC. The frequency and significance of cerebellar symptoms in tumors of the frontal lobes. Bulletin of the Neurological Institute of New York 1931;1:532-62.

52 Collier J. The false localising signs of intracranial tumour. Brain 1904;27:490-508.
53 de Ajuriaguerra J, Hécaen $\mathrm{H}$, Angelergues $\mathrm{R}$. Les apraxies. Variétés cliniques et lateralisation lésionelle. Rev Neurol 1960;102:28-57.

54 Hartmann F. Beiträge zur Apraxielehre. Monatsschrift für Psychiatrie und Neurologie 1907;21:97-274

55 Crigel E, Arseni C. Apraksia hodbbi (Gait apraxia). Shurnal Nevropatologi i Psichiatri Imeni S.S. Korsakova (Moskva). Korsakov's Journal of Neuropathology and Psychiatry] 1958;58:926-8.

56 Abraham K. Beiträge zur Kenntins der motorischen Apraxie auf Grund eines Falles von einseitiger Apraxie. Centralblatt für Nervenheilkunde und Psychiatrie 1907;30:161-76.

57 Kroll M. Beiträge zum Studium der Apraxie. Zeitschrift für Neurologie 1910;2:315-45.

58 Brun R. Klinische una anatomische Studien über Apraxie. Schweize Archiv für Neurologie und Psychiatrie 1921;9:29-64, 194-226.

59 Brun R. Klinische und anatomische Studien über Apraxie. Schweizer Archiv für Neurologie und Psychiatrie 1922;10:48-7, 185-210.

60 Dimitz L, Schilder P. Zur Symptomatologie der Stirnhirntumoren. Medizinische Klinik 1922:9:273-74.

61 Delmas-Marsalet $\mathbf{P}$. Lobe frontale et équilibre. Encephale 1936;31:15-91.

62 Goldstein K. After effects of brain injuries in war. New York: Grune and Stratton, 1942.

63 Adams K, Victor M, Ropper AH. Principles of neurology. New York: MacGraw-Hill, 1997

64 Kurlan R, Richard IH, Papka M, et al. Movement Disorders in Alzheimer's disease: more rigidity of definition is needed. Mov Disord 2000;15:24-9.

65 von Malaise E. Studien über die Grundlagen seniler Getstörungen. Zeitschrift für Psychiatrie 1910;46:902-1009.

66 Mingazzini G, Ciarla E. Klinischer und pathologisch-anatomische Beitrag zum Studium der Apraxie (Anatomical and pathological investigation on apraxia). Jahrbuch der Psychiatrie und Neurologie 1920:40:24-98.

67 Oldfield RC. The assessment and analysis of handedness: the Edinburgh inventory. Neuropsychologia 1971;9:97-113

68 De Renzi E, Lucchelli F. Ideational apraxia. Brain 1988;111:1173-85.

69 Denny-Brown D, Chambers RA. The parietal lobe and behaviour. Research Publications: Association for Research in Nervous and Mental Disease 1958:36:35-117.

70 Tweedy J, Reding M, Garcia C, et al. Significance of cortical disinhibition signs. Neurology 1982;32:169-73.

71 Luria AR. Higher cortical functions in man. New York: Basic Books, 1966 .

72 Goetz LG, Pappert E. Texbook of clinical neurology. Philadelphia: Saunders, 1999

73 Liepmann H. Die linke Hemisphäre und das Handeln (Left hemisphere and action performance). Münchner Medizinische Wochenscrift 1905:49:2322-6, 2375-8

74 Boccardi E, Della Sala S, Motto C, et al. Utilisation behaviour consequent to bilateral SMA softening. Cortex 2001 (in press).

75 Della Sala S, Gray C, Spinnler H, et al. Frontal lobe functioning in man the riddle revisisted. Archives of Clinical Neuropsychology 1998; 13:663-82.

76 Lhermitte F. "Utilization behaviour" and its relation to lesions of the frontal lobes. Brain 1983;106:237-55.

77 Brazzelli M, Colombo N, Della Sala S, et al. Spared and impaired cognitive abilities after bilateral frontal damage. Cortex 1994;30:27-51.

78 De Renzi E, Motti F, Nichelli P. Imitating gestures: a quantitative approach to ideomotor apraxia. Arch Neurol 1980;37:6-10.

79 De Renzi E, Faglioni P, Scarpa M, et al. Limb apraxia in patients confined to the left basal ganglia and thalamus. I Neurol Neurosurg Psychiatry 1986;49: 1030-8.

80 Bizzozero I, Costato D, Della Sala S, et al. Upper and lower face apraxia: role of the right hemisphere. Brain 2000;123:2213-30.

81 Della Sala S, Spinnler H, Venneri A. Un test di aprassia della faccia: dati normativi e validazione su cerebrolesi sinistri e dementi di Alzheimer. Archivio di Psicologia, Neurologia e Psichiatria 1998;59:346-55.

82 De Renzi E, Pieczuro A, Vignolo AL. Oral apraxia and aphasia. Cortex 1966:2:50-73

83 Poeck K, Kerschensteiner M. Analysis of sequencial motor events in ora apraxia. In: Zülch K, Kreutzfeld O, Galbraith G, eds. Otfried Förster Symposium. Berlin: Springer, 1975;98-109.

84 Bonfiglio F. Concerning special findings in a case of probable cerebra syphilis. Rivista Sperimentale di Freniatria e Medicina Legale delle Alienazioni Mentali 1908;34:196-206.

85 Estanol BV. Gait apraxia in communicating hydrocephalus. J Neurol Neurosurg Psychiatry 1981;44:305-8.

86 Fisher CM. Hydrocephalus as a cause of disturbances of gait in the elderly. Neurology 1982;32:1358-63.

87 Corkill RG, Cordoux-Hudson TAD. Normal pressure hydrocephalus: developments in determining surgical prognosis. Curr Opin Neurol 1999; 12:671-7.

88 Laiacona M, De Santis A, Barbarotto R, et al. Neuropsychological follow-up of patients operated for aneurysms of anterior communicating artery. Cortex 1989;25:261-73.

89 Faglioni $\mathbf{P}$, Basso A. Historical perspectives on neuroanatomical correlates of limb apraxia. In: Roy EA, ed. Neuropsychological study of apraxia and related disorders. Amsterdam: North Holland, 1985;3-44.

90 Marchetti C, Della Sala S. On crossed apraxia: description of a right-handed apraxic patient with right supplementary motor area damage. Cortex 1997;33:341-54. 
91 Watson RT, Fleet WS, Rothi LG, et al. Apraxie and the supplementary motor area. Arch Neurol 1986;43:787-92.

92 Verfaeille $M$, Heilman KM. Response preparation and response inhibition after lesions of the medial frontal lobe. Arch Neuro 1987:44:1265-71.

93 Della Sala S, Marchetti C, Spinnler H. The anarchic hand: a fronto-mesial sign. In: Boller F, Grafman J, eds. Handbook of neuropsychology. Amsterdam: Elsevier, 1994;233-55.

94 Banks G, Short P, Martinez AN, et al. The alien hand syndrome. Clinical and post-mortem findings. Arch Neurol 1989:46:456-9.

95 Chan JL, Chen RS, Ng KK. Leg manifestation in alien hand syndrome. $J$ Formos Med Assoc 1996;95:342-6.

96 Marchetti C, Della Sala S. Disentangling the alien and anarchic hand. Cognitive Neuropsychiatry 1998;3:191-207.

97 van Vleuten CF. Linksseitige motorische Apraxie. Ein Beitrag zur Physiologie des Balkens. Allgemeine Zeitschrift für Psychiatrie 1907;64:203-39.

98 Parrisius W. Greifreflex bei Hirntumor. Beitrag zum Studium des Sitzes der Zentren einiger komplizierten Reflexbewegungen. Deutsche Zeitschrift für Neurologie 1921:67:29-40.

99 Schuster P, Pinéas $H$. Weitere Beobachtungen über Zwangsgreifen und Nachgreifen und deren Beziehungen zu ähnlichen Bewegungstörungen. Zeitschrift für die gesamte Psychiatrie une Neurologie 1926;83:16-56.

100 De Renzi E, Faglioni P. Apraxia. In: Denes G, Pizzamiglio L, eds. Handbook of clinical and experimental neuropsychology. Hove, UK: Psychology Press, 1999.

101 Liepmann H. Drei Aufsätze aus dem Apraxiegebiet. Berlin: Krager, 1908.

102 Denes G, Mantovan MC, Gallana A, et al. Limb-kinetic apraxia. Mov Disord 1998;13:468-76

103 Heilman KM, Meador KJ, Loring DW. Hemispheric asymmetries of limb-kinetic apraxia. A loss of deftness. Neurology 2000;55:523-6
104 Rothi LJG Ochipa C, Heilman KM. A cognitive neruopsychological model of limb apraxia. Cognitive Neuropsychology 1991;8:443-58.

105 Rothi LJG, Ochipa C, Heilman KM. A cognitive neuropsychological model of limb praxis and apraxia. In: Rothi LG, Heilman KM, eds. Apraxia, the neuropsychology of action. Hove, UK: Psychology Press, 1997:22-49.

106 Lüders HO, ed. Supplementary sensorymotor area. Philadelphia: Lippincott-Raven, 1996.

107 Fuster JM. Memory in the cerebral cortex: an empirical approach to neuronal networks in the human and nonhuman primate. Cambridge: MIT Press, 1995

108 Luu P, Flaisch T, Tucker DM. Medial frontal cortex in action monitoring. J Neurosci 2000;20:464-9

109 Heilman KM, Rothi LJG. Limb apraxia: a look back. In: Rothi LJG Heilman KM, eds. Apraxia, the neuropsychology of action. Hove, UK: Psychology Press, 1997;7-18.

110 Feuchtwanger E. Di Funktionem des Stirnhirns. Ihre Pathologie und Psychologie. Berlin: Springer, 1923.

111 Marie $\mathbf{P}$, Bouttier $\mathrm{H}$, van Bogaert $\mathrm{L}$. Sur un cas de tumeur préfrontale droite. Trouble de l'orientation dan l'èspace. Rev Neurol 1924;11:209-21.

112 Adie WJ, Critchley M. Forced grasping and groping. Brain 1927:50:142-70.

113 Bell A. Apraxia in corpus callosum lesion. Journal of Neurology and Psychopathology 1934:15:137-46.

114 Maas O, Sittig O. Zur Frage der Verteilung der motorischen Apraxie auf die Körperteile. Monatsschrift für Psychiatrie und Neurologie 1929;73:40-51

115 Ethelberg S. On changes in circulation through the anterior cerebral artery: a clinico-angiographical study. Acta Psychiatrica et Neurologica (Suppl) 1951;75:12-211.

116 Damasio H, Damasio AR. Lesion analysis in neuropsychology. New York: Oxford University Press, 1989. 